\title{
Outorga onerosa do direito de construir e transferência do direito de construir: instrumentos de política urbana para proteção do patrimônio histórico cultural
}

\author{
Raquel de Barros Gaidex \\ Mestranda em Gestão Urbana na PUC/PR, Pontifícia Universidade \\ Católica do Paraná, PPGTU - Programa de Pós-Graduação em \\ Gestão Urbana, Rua Imaculada Conceição, 1155, Prado Velho, \\ Curitiba, PR, CEP 80215-901, (41) 32712623, rgaidex@gmail.com

\section{Zulma Schussel} \\ Arquiteta, doutorado em Meio Ambiente e Desenvolvimento pela \\ UFPR, professora titular do PPGTU - Programa de Pós-Graduação \\ em Gestão Urbana, Pontifícia Universidade Católica do Paraná, \\ Rua Imaculada Conceição, 1155, Prado Velho, Curitiba, PR, CEP \\ 80215-901, (41) 3271-2623, zulmas@terra.com.br
}

\begin{abstract}
Resumo
A partir de pesquisa bibliográfica, o presente artigo apresenta o estudo dos instrumentos da política urbana - outorga onerosa e transferência do direito de construir - estabelecidos pelo Estatuto da Cidade, aplicados à proteção ao patrimônio histórico, comparativamente aos institutos jurídicos do tombamento e inventário. Apresenta ainda, o estudo de caso de Curitiba, um dos primeiros municípios a utilizar esses instrumentos, que serviu como modelo ao Estatuto da Cidade e aos demais municípios brasileiros. Nas considerações finais são identificados os problemas gerados junto ao mercado da construção civil, em função dos procedimentos legais referentes à transferência do direito de construir.
\end{abstract}

Palavras-chave: patrimônio histórico, outorga onerosa e transferência do direito de construir.

o se comparar a propriedade urbana e a propriedade rural, observa-se que na propriedade rural, o seu valor encontra-se diretamente relacionado ao que se pode nela produzir e à sua escassez. $\mathrm{Na}$ propriedade urbana, por sua vez, a riqueza advém principalmente da sua inserção no contexto da cidade, que se traduz na sua acessibilidade.

Dessa forma, o potencial de exploração de uma propriedade urbana dependerá sempre da existência ou criação de uma infraestrutura pública (gerada com recursos advindos de toda a coletividade), sem a qual a atividade aplicada à propriedade individual não se viabiliza. Por sua vez, a destinação que o proprietário dá à sua propriedade tende a gerar externalidades que afetam a toda a coletividade. Se tal finalidade envolve a alocação de um significativo contingente populacional ou de um polo gerador de tráfego, haverá, cedo ou tarde, a saturação da infraestrutura viária, de transportes públicos ou das redes de suporte a outros serviços essenciais. De resto, as condições ambientais, de habitabilidade, paisagísticas, de salubridade, enfim, todo o meio ambiente urbano, são afetadas conforme o uso que se dá à propriedade inserida no contexto da cidade. (MARQUES NETO, 2002).

Por sua vez, o uso da propriedade está sujeito a regras de direito urbanístico, que impõem restrições, condicionamentos e mesmo sacrifícios para a utilização da propriedade. Em razão da subsunção do uso da propriedade às normas urbanísticas, instalou-se, há tempos no Brasil, uma discussão acerca da separação entre o direito de propriedade e o direito de construir. Essa dicotomia gerou outra polêmica sobre o instituto da outorga do direito de construir, também conhecido como "solo criado". 
O "solo criado", no Brasil, nasceu da ideia aceita em outros países de que seria tecnicamente possível a criação de área horizontal, mediante edificação sobre ou sob a superfície natural do solo ou, ao mesmo tempo, acima e abaixo dela. De tal sorte, tudo o que fosse construído acima ou abaixo da superfície do imóvel considerado seria "solo criado", ressalvadas as simples ocupações do espaço aéreo e do subsolo, destituídas de áreas úteis. (GASPARINI, 2008).

SILVA (1995) atribui à tecnologia das construções o surgimento de edificações com pisos artificiais sobrepostos ou subpostos, estabelecidos como unidades autônomas em relação ao solo natural configurado pela superfície do lote. Isso possibilita a multiplicação do solo edificável em "tantos novos solos quantos desses pisos artificiais sejam admitidos construir pela legislação edilícia ou de zoneamento".

No entanto, essa noção de "solo criado" é de pouca valia se não vier garantida, por força de lei ou de princípios jurídicos, pela separação do direito de construir do direito de propriedade. Assim, o "solo criado" passa a ser um bem economicamente apreciável, na medida em que se adotam instrumentos legais que lhe dão garantia, e que são colocados à disposição dos interessados.

Para se entender a separação entre o direito de propriedade e o direito de construir, é necessário ter claramente estabelecido que a propriedade de um terreno não significa um poder ilimitado sobre ele. A própria existência de normas urbanísticas (código de obras, leis de parcelamento, leis de uso e ocupação do solo, normas ambientais) já representa um limitador, que impede que o proprietário ocupe o terreno da forma que desejar. Assim, em certas áreas da cidade não é possível implantar indústrias ou comércio de grande porte e, em encostas muito íngremes ou beiras de rios não se pode construir e assim por diante. (ROLNIK, 2002).

Uma das primeiras vezes em que o instrumento do " "solo criado" " foi mencionado no Brasil ocorreu em São Paulo, em 1976, quando o prefeito Olavo Setúbal lançou a proposta de estabelecer um sistema que assegurasse a todos os proprietários de terrenos urbanos o direito de construir uma área proporcional à área do terreno (coeficiente de aproveitamento ou índice de aproveitamento igual a um). O interessado em construir além da área de seu terreno adquiriria do Poder Público o direito de construção da área excedente. O valor pago por este direito de construção serviria para dotar a região de equipamentos urbanos necessários para suprir a demanda oriunda do adensamento provocado pelas novas construções. (BRASIL, 2005)

A inspiração para o modelo proposto em São Paulo decorreu de dois institutos: o "limite legal de densidade" (plafond legal de densité) que, em 1975, foi instituído para o território francês e a experiência da transferência de potencial construtivo (transfer of development right) instituída pelo Plano de Chicago em 1973. (BRASIL, 2005).

No entanto, a proposta de institucionalização do "solo criado" ou outorga do direito de construir, na época gerou muitas controvérsias e foi abandonada. No início da década de 1980, o debate em torno da institucionalização do "solo criado" voltou a emergir em algumas cidades, desta vez vinculado à preservação do patrimônio histórico e, em 1992, em Curitiba, foi instituído o "incentivo construtivo" para imóveis tombados (Lei Municipal 6.337/82).

\section{O "solo criado" e a outorga onerosa do direito de construir}

O termo "solo criado" traz a ideia de aumento do solo edificável, enquanto que a expressão "outorga onerosa do direito de construir" implica em imposição de contrapartida pela aquisição do direito de construir. Por ser o primeiro termo mais abrangente, optou-se por utilizá-lo no decorrer deste trabalho.

A partir dos anos 90, em algumas cidades do Brasil, tais como Porto Alegre e Curitiba, se estabelecia o "solo criado" diferenciado sobre o zoneamento. Nos modelos adotados em Porto Alegre e Curitiba, foi definido um aumento potencial prévio acima do zoneamento em vigor para uma determinada área da cidade, que poderia ser concedido de forma onerosa para quem quisesse praticá-lo sobre seu terreno. Nesta fórmula, se mantinha os diferenciais do zoneamento, porém se definia claramente o estoque e limites máximos e a área onde o "solo criado" poderia ser outorgado. (BRASIL, 2005).

A versão do Estatuto da Cidade sobre o tema abre diversas possibilidades de interpretação do "solo 
criado". Em relação à transferência de potencial construtivo, o Estatuto da Cidade incorpora as experiências municipais de aplicação para a finalidade de proteção do patrimônio histórico e ambiental, e amplia para a implantação de equipamentos urbanos e comunitários, assim como para programas de regularização fundiária e de habitação de interesse social. (ROLNIK, 2002).

Juridicamente, a premissa necessária para a aplicação do "solo criado" é a separação entre o direito de propriedade e o direito de construir. O primeiro é, em uma sociedade capitalista, inviolável; isso não significa, porém, que ele não possa ser, mesmo em uma tal sociedade, limitado por razões de interesse coletivo, por exemplo, regulando-se e restringindose o segundo. O "solo criado" tem sido objeto de diferentes controvérsias, como aquela em torno da sua natureza de tributo em sentido estrito ou não. É, também, um instrumento complexo, interessante e multifacetado, cuja aplicação, se bem que não seja simples e exija cuidados, pode valer a pena (SOUZA, 2008).

Segundo Dallari (2007), o direito de propriedade é consagrado na Constituição Federal, juntamente com a função social da propriedade. Sendo assim, um dos problemas que se coloca é se a lei do plano diretor pode dar novo conteúdo ao direito de construir com base no dispositivo constitucional (art. 182, § $2^{\circ}$ ), que estabelece que a propriedade urbana cumpre sua função social quando atende às exigências fundamentais de ordenação da cidade expressas no plano diretor.

Raquel Rolnik (2002) observa que o "solo criado" é um instrumento de indução da implementação dos objetivos da política urbana, no sentido da redistribuição de oportunidades imobiliárias na cidade. Porém, a autora ressalta que sua implementação poderá ser maléfica se focalizar prioritariamente a geração de recursos adicionais para a receita municipal. A geração de recursos para investimentos municipais poderá ser um subproduto da aplicação da outorga onerosa, mas de forma alguma, seu objetivo principal, uma vez que isto resultaria numa flexibilização, e no limite, a destruição do controle do uso e ocupação do solo.

O art. 31 do Estatuto da Cidade vincula a aplicação dos recursos auferidos com a outorga onerosa às finalidades dispostas no art. 26 do mesmo diploma, que são: i) regularização fundiária; ii) execução de programas e projetos habitacionais de interesse social; iii) constituição de reserva fundiária; iv) ordenamento e direcionamento da expansão urbana; v) implantação de equipamentos urbanos e comunitários; vi) criação de espaços públicos de lazer e áreas verdes; vii) criação de unidades de conservação ou proteção de outras áreas de interesse ambiental; viii) proteção de áreas de interesse histórico, cultural ou paisagístico.

Esta disposição torna o preceito legal um importante instrumento de controle, pois se presta a evitar que os recursos auferidos com a alienação do potencial construtivo se transformem em receitas públicas desvinculadas do cumprimento das finalidades de ordenação e planejamento urbano.

\section{A proteção ao patrimônio histórico cultural}

Para o entendimento do conceito de patrimônio histórico, partimos do conceito de patrimônio público, definido na Lei de Ação Popular - Lei nº 4.717/65, em seu art. $1^{\circ}, \S 1^{\circ}$, como o conjunto de "bens e direitos de valor econômico, artístico, estético, histórico ou turístico". A Constituição Federal de 88 ampliou o objeto da ação popular, para incluir a moralidade administrativa, o meio ambiente e o patrimônio histórico cultural (art. $5^{\circ}$, LXXIII); portanto, podemos concluir que estes valores também foram incluídos no conceito legal de patrimônio público.

A expressão patrimônio cultural tem sido utilizada pela doutrina para referir-se ao conjunto dos bens e interesses que exprimem a integração do homem com o meio ambiente (tanto o natural como o artificial), como aqueles de valor artístico, estético, histórico, turístico, paisagístico ou arqueológico, nesse rol incluídos os valores até mesmo imateriais referentes à identidade, à ação e à memória dos diferentes grupos formadores da sociedade brasileira. (MAZZILLI, 2008).

Um conceito clássico de patrimônio histórico cultural e artístico nacional, é aquele que "abrange todos os bens, móveis e imóveis, existentes no país, cuja conservação seja de interesse público, por sua vinculação a fatos memoráveis da história pátria, 
ou por seu excepcional valor artístico, arqueológico, etnográfico, bibliográfico ou ambiental" (MEIRELLES, 1991)

Os bens incluídos no conceito de patrimônio histórico cultural e artístico podem ser realizações humanas, obras da natureza; podem ser criações contemporâneas ou podem ser relíquias do passado.

De acordo com o artigo 216 da Constituição Federal, qualquer bem, material ou imaterial, singular ou coletivo, móvel ou imóvel, é incluído no patrimônio cultural brasileiro, desde que seja portador de referência à identidade, à ação, à memória dos diferentes grupos formadores da nacionalidade ou sociedade brasileira.

\section{O tombamento e a proteção dos bens de valor artístico ou histórico}

Seguindo a tradição do direito português, onde se originou o instituto do tombamento, o direito brasileiro utiliza a expressão "tombar" no sentido de registrar, inventariar. Os bens eram inscritos nos arquivos do Reino e eram guardados na Torre do Tombo. (MEIRELLES, 1991).

No direito brasileiro, o Poder Público, pelo tombamento, protege determinados bens, que são considerados de valor histórico ou artístico, determinando a sua inscrição nos "Livros do Tombo", ficando os bens, em decorrência disso, sujeitos a restrições parciais, porquanto o bem, ainda que pertencente a particular, passa a ser considerado bem de interesse público. De acordo com o art. $1^{\circ}$ do Decreto-lei $n^{\circ} 25$, de 1937, o conceito de tombamento, conjugado com o conceito de patrimônio histórico e artístico nacional, é expresso como:

o conjunto dos bens móveis e imóveis existentes no país cuja conservação seja de interesse público, quer por sua vinculação a fatos memoráveis da história do Brasil, quer por seu excepcional valor arqueológico ou etnográfico, bibliográfico ou artístico.

O tombamento é definido como a declaração pelo Poder Público do valor histórico, artístico, paisagístico, turístico, cultural ou científico de coisas ou locais que, por essa razão, devam ser preservados, de acordo com a inscrição em livro próprio (MEIRELLES, 1991).
SOUZA FILHO (2006) assinala que o tombamento individualiza o bem, seja coletivo ou singular, colocando-o sob um regime especial que inclu a proibição peremptória de o mutilar, destruir ou demolir, e a exigência de autorização expressa para obras de reparação, restauro ou mesmo pintura.

Quanto à natureza jurídica do tombamento, dois aspectos são apontados pelos doutrinadores como de efetiva importância: se o tombamento é ato vinculado ou discricionário; e se a limitação imposta pelo tombamento constitui uma limitação administrativa à propriedade, ou se constitui servidão administrativa.

Quanto ao primeiro aspecto, alguns autores, tais co-mo Meirelles (1991) consideram o tombamento como ato vinculado, argumentando que a Administração tem o poder-dever de tombar o bem considerado relevante para o patrimônio cultural.

Em sentido oposto, outros autores consideram o tombamento como ato discricionário. Maria Sylvia Zanella DI PIETRO (2006) se coloca entre os que consideram o tombamento ato discricionário. E justifica:

Ocorre que o patrimônio cultural não é o único bem que compete ao Estado proteger. Entre dois valores em conflito, a Administração terá que zelar pela conservação daquele que de forma mais intensa afete os interesses da coletividade. Essa apreciação terá que ser feita no momento da decisão, diante do caso concreto; evidentemente, se nenhuma razão de interesse público obstar o tombamento, este deve ser feito; por isso mesmo, a recusa em fazê-lo há de ser motivada, sob pena de transformar-se a discricionariedade em arbítrio que afronta a própria Constituição, na parte em que protege os bens de interesse público (DI PIETRO, 2006).

Quanto ao segundo aspecto, também não há unanimidade entre os autores. Enquanto alguns entendem que o tombamento constitui modalidade de servidão administrativa, outros o encaram como limitação ao direito de propriedade.

Certos autores preferem considerar o tombamento como categoria própria, não se enquadrando nem como limitação administrativa, e tampouco como servidão administrativa, argumentando que: 
o tombamento tem em comum com a limitação administrativa o fato de ser imposto em benefício de interesse público; porém dela difere por individualizar o imóvel. Comparado com a servidão, o tombamento a ela se assemelha pelo fato de individualizar o bem; porém dela difere porque falta a coisa dominante, essencial para caracterizar qualquer tipo de servidão, seja de direito público ou privado. (DI PIETRO, 2006)

No que tange à indenização, autor José Eduardo Ramos Rodrigues (1995) adota o entendimento de que a discussão sobre se o tombamento é indenizável ou não, escapa à realidade fática brasileira.

Segundo a Constituição de 1988, cumpre ao Poder Público defender o Patrimônio Cultural Brasileiro, sendo um de seus meios mais eficazes o tombamento, exatamente por não representar ônus excessivo ao erário público. Se entendermos que cada vez que um bem cultural for tombado, haverá indenização ou desapropriação indireta, estaremos objetivamente impedindo a preservação do patrimônio cultural e o cumprimento dos desígnios constitucionais.

O tombamento é o mais conhecido dos instrumentos de proteção do patrimônio histórico cultural, elen-cados no art. 216, § $1^{\circ}$ da CF. Constituem outras formas de acautelamento e preservação, de acordo com o $\S 1^{\circ}$ do art. 216, o inventário, registros, vigilância, desapropriação e outros instrumentos. Portanto, é dever do Poder Público, seja União, Estado ou Município, seja através do Poder Executivo, Legislativo ou Judiciário, proteger os bens integrantes do patrimônio cultural por meio de quaisquer formas de acautelamento ou preservação, desde que tenham algum fundamento legal.

Desta forma, para que se consiga a efetiva proteção dos bens de interesse histórico cultural, o Poder Legislativo tem competência para, através de lei específica, determinar a preservação do bem por seu valor histórico, cultural, paisagístico, arquitetônico, entre outros.

É importante que neste ato legislativo se estabeleça claramente a subordinação à legislação específica, o regime jurídico a que ficará sujeita a coisa cujo valor se declara, e a qual órgão de preservação o bem, ou os bens, estarão sob proteção.
No entanto, diríamos que, face o posicionamento do Poder Judiciário em algumas decisões em que privilegia o direito de propriedade em detrimento da preservação do bem de valor histórico cultural, por ausência de lei específica determinando a proteção do bem, é necessário que se utilize, não só o instituto do tombamento, como também instrumentos de menor complexidade. Assim, a Constituição Federal, em seu artigo 216 , § $1^{\circ}$, prevê outros instrumentos de proteção, tais como, inventários, registros, vigilância, desapropriação e outras formas de acautelamento e preservação.

O tombamento era visto, antes da Constituição de 1988, de forma equivocada, como o único instrumento de preservação do patrimônio cultural existente no ordenamento jurídico nacional. Por força do disposto no art. $216, \S 1^{\circ}$, o tombamento passou a ser apenas um desses instrumentos. Mas, mesmo assim, ainda é comum se confundir o tombamento com proteção ao patrimônio cultural. Porém, ressaltese que a proteção pode se dar por diversas formas ou instrumentos, entre eles, o tombamento, mas não só por ele. (MIRANDA, 2012)

Miranda (2012) destaca ainda que o tombamento é uma das muitas formas de preservação de um bem que possui valor cultural ou histórico. Entretanto, a preservação não possui uma única face, traduzindo-se, em verdade, num conjunto de ações que podem ser tomadas pelo Poder Público ou mesmo por particulares que visem à manutenção da memória de uma população com referência a fatos e dados históricos, nos termos preconizados pela Constituição.

\section{O inventário de bens de valor histórico e cultural}

Dentre os diversos instrumentos de preservação indicados pelo legislador constitucional no $\S 1^{\circ}$ do art. 216, merece destaque o inventário de bens de valor histórico e cultural, que pode ser definido como um cadastro de bens de valor sócio cultural, sendo que esses bens podem ser de domínio público ou particular.

Tendo sido instituído como um dos instrumentos de proteção aos bens de valor histórico e cultural, o inventário encontra amparo legal na Constituição Federal, em seu art. 216, $\S 1^{\circ}$, quando afirma 
que "o Poder Público, com a colaboração da comunidade, promoverá e protegerá o patrimônio cultural brasileiro, por meio de inventários, registros, vigilância, tombamento e desapropriação, e de outras formas de acautelamento e preservação".

A Constituição Federal de 1988 define o patrimônio cultural brasileiro como os bens de natureza material e imaterial, tomados individualmente ou em conjunto, portadores de referência à identidade, à ação, à memória dos diferentes grupos formadores da sociedade brasileira.

Na esfera federal, o inventário ainda não foi regulamentado e poucos Estados e Municípios brasileiros possuem essa relação de bens que se constitui no inventário, e cuja importância histórica e cultural é reconhecida por técnicos especializados nas mais diversas áreas - arquitetura, artes plásticas, história, folclore, entre outros.

A inventariação pode ser realizada de maneira mais rápida que o tombamento, mostrando-se como uma medida administrativa célere e eficiente principalmente em casos em que a atuação do Poder Público tenha que ser urgente. Miranda (2012) alerta, porém, que o bem inventariado como patrimônio cultural também se submete a medidas restritivas quanto ao seu uso, gozo, e disposição, tornando-se obrigatória a sua preservação e conservação.

\section{A proteção do patrimônio histórico cultural e a função social da propriedade}

A questão da preservação de bens históricos e culturais sempre vem acompanhada do estudo do direito de propriedade. Não há como negar a relação existente entre a tutela do patrimônio cultural e o direito de propriedade, uma vez que qualquer ação voltada à preservação de bens históricos e culturais implica necessariamente numa interferência no direito de propriedade. Essa interferência é imposta tanto ao Poder Público como ao particular.

O art. 50, inciso XXII da Constituição Federal garante o direito de propriedade, e no inciso XXIII se encontra assegurada a sua função social. Assim, o direito concedido ao proprietário de usar, gozar, e dispor do bem está limitado pelo princípio constitucional da função social da propriedade, de tal maneira que não se pode conceber a existência deste direito sem a restrição existente em prol da coletividade.

Também no art. 170, inciso III da Constituição Federal, no Título VII, que se refere à Ordem Econômica e Financeira, está escrito, dentre os princípios destinados a assegurarem uma existência digna, o da função social da propriedade.

O Código Civil Brasileiro, em seu art. 1.228 praticamente reproduz o art. 524 do Código Civil de 1916, elencando as faculdades inerentes ao domínio: "de usar, gozar e dispor da coisa, e o direito de reavê-la do poder de quem quer que injustamente a possua ou detenha".

Já o parágrafo primeiro do mesmo artigo traz inovações, quando estabelece que o direito de propriedade deve atender também à preservação da flora, fauna, belezas naturais, equilíbrio ecológico e o patrimônio histórico e artístico "de conformidade com o estabelecido em lei especial, a flora, a fauna, as belezas naturais, o equilíbrio ecológico e o patrimônio histórico e artístico, bem como evitada a poluição do ar e das águas".

Uma vez que não há proteção ao direito de propriedade sem o respeito à sua função social, conforme se depreende do $\S 1^{\circ}$ do art. 1.228 do Código Civil, o proprietário de um bem de interesse histórico cultural está adstrito a observar as limitações oriundas do respeito ao direito coletivo na preservação do bem.

Não se concebe que um bem de reconhecido valor sócio cultural venha a ser demolido, reformado, danificado, mutilado, apagado impunemente pelo proprietário, como se o direito de propriedade ainda existisse no e para o exclusivo interesse do titular. Tanto é esse o senso comum que o legislador federal houve por bem inserir na recente lei que define crimes ambientais diversas condutas lesivas ao patrimônio cultural. (MARCHESAN, 2014)

Ainda por entender que o proprietário do bem de interesse histórico cultural deverá usufruí-lo em benefício da coletividade, a autora assim conclui:

É por essa razão que se entende não ser indenizável o tombamento de um bem de valor cultural. O ato de tombamento não afeta o núcleo do direito de propriedade, preservando o direito de alienação 
(jus disponendi) e mantendo os direitos de uso e gozo sobre a res, direitos esses últimos que ficam apenas restringidos pela impossibilidade de alteração do bem como um todo ou de parte dele. Entretanto, o proprietário pode continuar tirando proveito econômico da coisa, sendo-Ihe acrescido o ônus de preservá-la. Devido a esse encargo, defende-se benefícios fiscais aos proprietários (como, por exemplo, isenção ou redução de IPTU; desconto parcial ou total no imposto de renda dos gastos na manutenção ou restauro do imóvel). (MARCHESAN, 2010).

Destas observações depreende-se que a proteção do patrimônio histórico cultural figura como uma das condições para o exercício do direito de propriedade. Assim, não pode o proprietário dispor do bem da maneira que the aprouver, ignorando o caráter social que possui hoje o direito de propriedade, conforme consagra a Constituição Federal, em seu art. 50, incisos XXII e XXIII: por um lado, a Lei Maior garante o direito de propriedade; porém, no dispositivo seguinte, determina que a propriedade atenderá a sua função social.

\section{Da transferência do direito de construir e da outorga onerosa do direito de construir}

Em alguns Estados e Municípios, o proprietário do bem de interesse histórico ou cultural goza de outros benefícios, além dos benefícios fiscais, tais como isenção ou redução de IPTU. Trata-se do incentivo constituído pela transferência do direito de construir, instrumento previsto na Lei $n^{\circ} 10.257 / 01$, em seu art. 4, inciso V, alínea "o", e art. 35 da mesma Lei.

Como a lei estabelece que o proprietário pode "exercer em outro local, ou alienar" o seu direito de construir, conclui-se que se está diante de mais um benefício concedido ao proprietário pela preservação do bem de interesse histórico.

MIRANDA (2012) afirma que a transferência do direito de construir tem sido utilizada como uma compensação ao proprietário do imóvel tombado, já que este não pode dispor do bem de forma plena, uma vez que fica impedido de proceder a ampliação ou demolição; neste último caso, poderia até mesmo realizar uma construção moderna e com elevado número de pavimentos. O autor ilustra sua afirmação com um exemplo:
Imagine-se que o proprietário de um bem imóvel tombado que tenha dois andares pudesse, se não ocorresse o tombamento do prédio, de acordo com as normas urbanísticas, edificar no local até o equivalente a seis andares. Com o tombamento advém a imodificabilidade do bem, impedindo, assim, o pleno exercício desse direito de construir, havendo um sacrifício do potencial construtivo equivalente à edificação de quatro andares. Nesse caso, o proprietário do imóvel tombado, havendo lei municipal em tal sentido, poderá exercer em outro local esse seu direito de construir, ou aliená-lo a terceiros mediante escritura pública. (MIRANDA, 2012)

Além do incentivo constituído pela transferência do direito de construir, existe também outra forma de preservar os bens de interesse histórico ou cultural, que é através da outorga onerosa do direito de construir, prevista no art.28 e seguintes das Lei $n^{\circ}$ 10.257/01

Ao se examinar o art. 26 da Lei n ${ }^{\circ}$ 10.257/01, contido na Seção VIII que trata do direito de preempção, temos que o direito de preempção "será exercido sempre que o Poder Público necessitar de áreas para: (...) VI. proteção de áreas de interesse histórico, cultural ou paisagístico."

Muitas vezes, alguns imóveis existentes possuem valor cultural ou servem à memória histórica de fatos relevantes para o Município. Ainda que o tombamento seja um instrumento útil para preservar um bem de interesse histórico ou cultural, pode surgir o interesse do Município em adquirir o bem para transformálo em algo que possa ser desfrutado por toda a comunidade, como um museu, ou um centro cultural, por exemplo. Para estes casos, a outorga onerosa do direito de construir é o instrumento adequado.

\section{Considerações finais}

Os dois instrumentos analisados - a outorga onerosa do direito de construir, e a transferência do direito de construir, ou transferência de potencial construtivo, são institutos que se prestam e se adequam perfeitamente à proteção do patrimônio histórico, principalmente pela sua característica de compensação à restrição que o proprietário do imóvel de interesse histórico sofre no exercício do direito de propriedade. 
Por meio da transferência do direito de construir, o proprietário pode exercer o seu direito de construir tanto no próprio imóvel, como exercê-lo em outra área, ou ainda, transferi-lo para outrem. No caso da outorga onerosa do direito de construir, o particular pode também adquirir do Poder Público o direito de construir além dos parâmetros estabelecidos, mediante contrapartida financeira. Este recurso irá financiar a aquisição de bem de interesse histórico ou cultural que seja de interesse de toda a comunidade. Portanto, são várias as possibilidades de se exercer o direito de construir e ainda assim, preservar os bens de interesse histórico.

No entanto, há que se apontar algumas observações a respeito da utilização destes instrumentos, primeiro de um modo geral, e depois tratandose especificamente dos instrumentos aplicados à proteção do patrimônio histórico cultural.

Em estudo desenvolvido por Furtado et al (2007), uma das conclusões é que o objetivo de arrecadação para gerar recursos financeiros para infraestrutura com fins sociais é o objetivo que norteia a maioria dos municípios. É de se considerar que este também é um objetivo privilegiado pelo Estatuto da Cidade.

O estudo aponta que os recursos obtidos com a aplicação da outorga onerosa do direito de construir são, em sua maioria, direcionados para investimentos públicos de caráter redistributivo, em áreas carentes das cidades. Assinala que algumas cidades canalizam a totalidade da arrecadação para investimentos específicos em habitação social, como é o caso de Curitiba. Em outras cidades, como Blumenau e São Luís, são direcionadas para implantação de equipamentos urbanos e comunitários.

Porém, a maioria das cidades que utilizam este instrumento, investem os recursos em programas variados, tais como programas em áreas de interesse social, regularização fundiária, criação e preservação de áreas verdes, preservação do patrimônio cultural, entre outros, de acordo com as diretrizes estabelecidas no plano diretor.

No dia a dia da gestão pública, se verifica que a atuação do poder público é decisiva na concorrência entre os dois institutos. Assim, se observa em Curitiba que, com o êxito obtido com a implementação dos dois instrumentos, o poder público estimulou a outorga onerosa do direito de construir como uma forma de obter recursos para os programas sociais, conforme aponta o estudo acima mencionado.

No entanto, face as exigências legais que cercam a utilização da transferência do direito de construir, (tais como registro imobiliário da transferência nas matrículas dos imóveis, tanto na matrícula do imóvel que dá origem ao potencial, quanto na matrícula do imóvel que recebe a transferência) este instituto acabou perdendo terreno para a outorga onerosa, de operacionalização bem mais simples, uma vez que o particular simplesmente adquire as cotas de potencial do Poder Público que, por sua vez, disponibiliza cada vez mais cotas no mercado para investimentos em programas sociais, assim como para implementação de equipamentos urbanos, preservação de áreas verdes, entre outros.

Dessa forma, com relação à proteção do patrimônio histórico, existem soluções diferenciadas para a utilização dos dois institutos, dependendo da realidade de cada município. Em Curitiba, por exemplo, observa-se uma falta de interesse dos empresários da construção civil, na aquisição de potencial construtivo oriundo de imóveis históricos, face às exigências relatadas no parágrafo anterior. Não há, no entanto, maiores dificuldades de colocação no mercado, por parte do Poder Público, de cotas de potencial construtivo, destinadas à preservação dos imóveis de interesse especial de preservação, os quais são preservados e restaurados através dos recursos obtidos com a utilização da outorga onerosa do direito de construir.

\section{Referências bibliográficas}

BRASIL. Estatuto da Cidade: guia para implementação pelos municípios e cidadãos. $4^{\mathrm{a}}$ ed. Brasília: Senado Federal, 2005

BRASIL. Lei $n^{\circ}$ 10.257/2001. Estatuto da Cidade. Regulamenta os arts. 182 e 183 da Constituição Federal, estabelece diretrizes gerais da política urbana e dá outras providências. Disponível em: <http://www. planalto.gov.br/ccivil_03/Leis/LEIS_2001/L10257. htm>. Acesso em 10.jan.2015.

BRASIL. Lei ${ }^{\circ}$ 4.717/1965. Lei de Ação Popular. Disponível em: <http://www.planalto.gov.br/ccivil_03/Leis/ L4717.htm>. Acesso em 28.dez.2014.

BRASIL. Constituição Federal de 1988. Disponível em: <http://www.planalto.gov.br/ccivil_03/Constituicao/ Constituicao.htm>. Acesso em: 28.dez.2014. 
BRASIL. Decreto-lei n² 25/1937. Organiza a proteção do patrimônio histórico e artístico nacional. Disponível em <http://www.planalto.gov.br/ccivil_03/Decreto-Lei/Del0025.htm>. Acesso em 10.jan.2015.

BRASIL. Lei $n^{\circ}$ 10.406/2002. Código Civil Brasileiro. Disponível em <http://www. planalto.gov.br/ccivil_03/ Leis/2002/L10406.htm>. Acesso em 10.jan.2015.

CURITIBA. Lei Municipal $n^{\circ}$ 6.337/1982. Institui incentivos construtivos para a preservação de imóveis de valor cultural, histórico ou arquitetônico. Disponível em $<$ http://www.leismunicipais.com.br>. Acesso em 10.jan.2015.

CURITIBA. Lei Municipal no 9.801/2000. Dispõe sobre os instrumentos de política urbana. Disponível em <www.leismunicipais.com.br>. Acesso em 10.jan.2015.

CURITIBA. Lei Municipal no 9.803/2000. Dispõe sobre a transferência de potencial construtivo. Disponível em <www.leismunicipais.com.br>. Acesso em 10.jan.2015.

CURITIBA. Lei Municipal no 11.266/2004. Dispõe sobre a adequação do Plano Diretor de Curitiba ao Estatuto da Cidade - Lei Federal $n^{\circ} 10.257 / 01$, para orientação e controle do desenvolvimento integrado do Município. Disponível em <www. leismunicipais.com. br>. Acesso em 10.jan.2015.

DALLARI, A. A. "Solo Criado": constitucionalidade da outorga onerosa de potencial construtivo. In: DALLARI, Adilson Abreu; DI SARNO, Daniela Campos Libório (Coord.). Direito Urbanístico e Ambiental. Belo Horizonte: Fórum, 2007.

DI PIETRO, M. S. Z. Direito administrativo. 19ª ed. São Paulo: Atlas, 2006

FURTADO, F. et al. Outorga onerosa do direito de construir: panorama e avaliação de experiências municipais. In: ENCONTRO DA ASSOCIACÃO NACIONAL DE PÓS-GRADUAÇÃO E PESQUISA EM PLANEJAMENTO URBANO E REGIONAL, 12,2007, Belém, PA. Disponível em: <http://www3.ufpa.br/xiienanpur/ CD/ARQUIVOS/GT1-328-90-20061218230629. pdf $>$. Acesso em 21/06/2014.

GASPARINI, D. Outorga Onerosa do Direito de Construir. In: AGRELLI, Vanusa Murta; SILVA, Bruno Campos (Coord.). Direito Urbanístico e Ambiental. Rio de Janeiro: Lumen Juris, 2008.
MARCHESAN, A. M.M. A Proteção Constitucional Ao Patrimônio Cultural. Disponível em: <http://www. mprs.mp.br/ambiente/doutrina/id9.htm>. Acesso em: 14 dez. 2014

MARCHESAN, A. M. M. A proteção constitucional e infraconstitucional do patrimônio cultural. In: MARCHESAN, Ana Maria Moreira. STEIGLEDER, Annelise Monteiro. CAPPELLI, Silvia (org.). Direito Ambiental. Porto Alegre: Verbo Jurídico, 2010.

MARQUES NETO, F. de A. Outorga Onerosa do Direito de Construir ("solo criado"). In: DALLARI, Adilson Abreu; FERRAZ, Sergio (Coord.). Estatuto da Cidade (Comentários à Lei Federal no 10.257/2001). São Paulo: Malheiros, 2002

MAZZILLI, H. N. A defesa dos interesses difusos em juízo: meio ambiente, consumidor, patrimônio cultural, patrimônio público e outros interesses. $21^{\text {a }}$ ed. São Paulo: Saraiva, 2008

MEIRELLES, H. L. Direito Administrativo Brasileiro. 16 ${ }^{\mathrm{a}} \mathrm{Ed}$ São Paulo: Revista dos Tribunais, 1991.

MIRANDA, M. P. de S. Tutela Constitucional do Patrimônio Cultural Brasileiro: O inventário como um novo instrumento de proteção. In: RODRIGUES, José Eduardo Ramos; MIRANDA, Marcos Paulo de Souza (coord.). Estudos de direito do patrimônio cultural. Belo Horizonte: Fórum, 2012.

RODRIGUES, J. E. R. Tombamento: Instrumento de Defesa do Patrimônio Cultural. Papel da Ação Civil Pública. In: MILARÉ, Édis (coord.). Ação Civil Pública. São Paulo: Revista dos Tribunais, 1995.

ROLNIK, R. Outorga Onerosa e Transferência do Direito de Construir. In: OSORIO, Letícia Marques (Org.). Estatuto da Cidade e Reforma Urbana: Novas Perspectivas para as Cidades Brasileiras. Porto Alegre: Sergio Fabris, 2002.

SILVA, J. A da. Direito Urbanístico Brasileiro. 2a ed. São Paulo: Malheiros, 1995.

SOUZA FILHO, Carlos Frederico Marés de. Bens culturais e sua proteção jurídica. Curitiba: Juruá, 2006.

SOUZA, M.L.de. $A B C$ do Desenvolvimento Urbano. Rio de Janeiro: Bertrand Brasil, 2008. 